\title{
Chronic Phase Chronic Myelogenous Leukemia, BCR-ABL1 Positive
}

National Cancer Institute

\section{Source}

National Cancer Institute. Chronic Phase Chronic Myelogenous Leukemia, BCR-ABL1

Positive. NCI Thesaurus. Code C3175.

A phase of chronic myelogenous leukemia in which the peripheral blood smear shows leukocytosis due mainly to neutrophils in different stages of maturation. Blasts usually account for less than $2 \%$ of the white blood cells counts. The platelet count is normal or increased. Thrombocytopenia is very uncommon during the chronic phase. Most patients have mild anemia. The bone marrow biopsy is hypercellular due to increased numbers of neutrophils and their precursors. Blasts usually account for fewer than 5\% of the marrow cells, and more than $10 \%$ indicates transformation to the accelerated phase. Megakaryocytes are smaller than normal and have hypolobated nuclei. The spleen is enlarged due to infiltration of the cords of the red pulp by granulocytes. Most patients with chronic myelogenous leukemia are diagnosed in the chronic phase, which usually has an insidious onset and may last from several months to several years. (WHO, 2001) 